\title{
APRENDIZAGEM EM EDUCAÇÃO A DISTÂNCIA - EAD: O DESAFIO DA FORMAÇÃO DE TUTORES ON-LINE, COM ENFASE NO RELACIONAMENTO INTERPESSOAL EM AMBIENTES VIRTUAIS DE APRENDIZAGEM - AVA
}

https://doi.org/10.29327/3860.11.20-9

Priscila da Silva Rodrigues Machado ${ }^{1}$

\section{RESUMO}

O presente artigo tem como objetivo principal trazer um estudo introdutório sobre o tema: construção de Ambientes Virtuais de Aprendizagens - AVA's - utilizando-se de instrumentos de interação como forma de aproximar tutor e educando. Limita-se a disponibilizar tais conhecimentos e não propõe nenhum modelo de AVA, apenas oferece subsídios para que sejam desenvolvidos novos AVA's que priorizem além do desenvolvimento cognitivo, as relações interpessoais, como meio favorável para uma aprendizagem relevante. Utiliza recursos bibliográficos de fontes diversas: teórica, legal e documental; fundamentando seus pressupostos em variados autores que realizaram importantes pesquisas em diferentes campos do conhecimento, como a psicologia, a história da aprendizagem, a educação à distância; assim como o embasamento legal vigente. Ressalta-se, também, uma reflexão sobre as diferentes funções exercidas pelo tutor on-line, que é o elo da relação ensino-aprendizagem proposta pelo AVA.

PALAVRAS-CHAVE: Teorias da aprendizagem. Legislação. Funções do tutor. Interação. Ética.

\section{LEARNING IN DISTANCE EDUCATION - EAD: THE CHALLENGE OF ON-LINE GUARDIAN TRAINING, WITH EMPHASIS IN INTERPERSONAL RELATIONSHIP IN VIRTUAL LEARNING ENVIRONMENTS - AVA}

\begin{abstract}
This article aims to bring an introductory study on the theme: building Virtual Learning Environments - AVAs - using interaction tools as a way to approach tutor and leaner. It merely provides such knowledge and does not propose any VLE model, it only provides support for the development of new VLEs that prioritize beyond cognitive development, interpersonal relationships, as a favorable means for relevant learning. It uses bibliographic resourses from various sources: theoretical, legal and documentary; basing their assumptions on various authors who have conducted important research in different fields of knowledge, such as psychology, the history of learning, distance education; as well as the current legal basis. It also highlights a reflection on the

\footnotetext{
${ }^{1}$ Pós-graduada em Educação a Distância e Tutoria em Educação a Distância pela Faculdade Internacional Signorelli,
} 
different functions performed by the online tutor, which is the linf of the teachinglearning relationship proposed by the VLE.

KEYWORDS: Theories of learning. Legislation. Functions of the tutor. Interaction. Ethic.

\section{INTRODUÇÃO}

A educação contemporânea brasileira está permeada por três fatores conflitantes: primeiro, as metodologias referenciadas numa didática ultrapassada, ainda com resquícios da educação jesuítica; segundo, uma formação docente que não está preparada para lidar com a interatividade, as mídias digitais e a agilidade da Era Informacional; e, por fim, os educandos, que trazem para o chão da escola uma imensa bagagem de conteúdos e vivências em constante construção. Tal conjuntura torna-se um imenso desafio a ser superado em toda a educação básica e superior.

Na tentativa de encontrar uma proposta a fim de subsidiar uma possível solução para esse impasse educacional, tem-se incentivado o uso da Educação a Distância EaD. Recentemente, houve alteração na Lei de Diretrizes e Bases da Educação Nacional - LDB 9.394/96 - enfatizando o uso das tecnologias e da EaD para a educação básica. O que demonstra uma preocupação governamental em aproximar educação e tecnologia.

$\mathrm{O}$ presente artigo originou-se do questionamento de como introduzir a $\mathrm{EaD}$ na educação formal de modo a conceber uma aprendizagem significativa com o mínimo de evasão escolar possível, o que é um grande desafio em Ambientes Virtuais de Aprendizagem - AVA.

Para que haja uma mudança responsável e consistente no uso da $\mathrm{EaD}$ se faz necessário analisar o embasamento teórico e legal, estabelecer objetivos viáveis, capacitar profissionais, entre outras medidas que produzam um ensino de qualidade. É o que, também, se pretende analisar com essa publicação. 
Diversos questionamentos foram abordados, todavia, observou-se que uma das situações mais sensíveis é capacitar tutores para $\mathrm{EaD}$, de modo que a relação interpessoal seja de proximidade e cative o educando afim de que se sinta instigado a estudar; mantendo uma relação entre tutor e educando próxima da que ocorre em uma sala de aula convencional.

Motivado por essas inquietações, o artigo propõe como objeto de estudo analisar a tutoria em $\mathrm{EaD}$ com base nas teorias da aprendizagem - com ênfase nas inteligências múltiplas, no desenvolvimento de competências e no desenvolvimento cognitivo -; na legislação vigente; na construção de modelos pedagógicos em $\mathrm{EaD}$; na função do tutor on-line e no desenvolvimento afetivo em AVA. A finalidade é apresentar uma reflexão sobre como proporcionar um local favorável para promover uma aprendizagem de qualidade.

Logo, a proposta desse artigo é sugerir uma base de sustentação epistemológica, de modo a desenvolver AVA's criativos e acolhedores afim de que o educando sinta-se próximo do educador, como em uma sala de aula convencional. Haja vista, que o homem é um ser social e que necessita manter relações interpessoais positivas; a interação se torna um fator imprescindível para promover uma aprendizagem relevante.

\section{APRESENTAÇÃO DO ENBASAMENTO, TEÓRICO E LEGAL, NORTEADOR PARA A FORMAÇÃO DE TUTORES}

Inicialmente é mister ressaltar a definição de tutor, ou instrutor, descrita por Michael Moore e Greg Kearsley:

Na abordagem sistêmica, o controle de qualidade pela avaliação contínua de todas as partes do sistema é muito importante. Um componente principal desse controle é a produção, a intervalos regulares, de um produto para cada aluno, geralmente, indicado como tarefa ou trabalho escolar. É a equipe de criação do curso que determina a tarefas com base no conteúdo de cada unidade de um curso, e as tarefas são realizadas por cada aluno, que as envia a seu instrutor por meio eletrônico ou pelo correio. Os instrutores corrigem, comentam, avaliam e comunicam suas observações, enviando o relatório de avaliação à administração da instituição, que o utiliza como parte do processo de monitoramento. (MOORE, 2007, p. 17). 
Observa-se que o referido autor enfatiza como função precípua do instrutor (tutor) a interação com o educando a fim de auxiliar o mesmo a aprender o conteúdo do curso. Isso se efetiva por meio de feedback das atividades e avaliações. Logo, percebese que a construção do conhecimento, muito além do conteúdo didático preparado pela equipe, é permeada pelo relacionamento interpessoal estabelecido entre tutor e educando.

Para contextualizar o momento histórico da educação brasileira, cita-se Patricia Alejandra Behar:

\begin{abstract}
O contexto em que estamos inseridos é complexo, relacional, dinâmico, objetivo/subjetivo, imprevisível, quantificável/qualificável. Portanto, quando se busca pesquisar um AVA, a visão que se tem desse contexto é de mobilidade, flexibilidade, alinearidade, presenteísmo, pertinência e eficiência. Retoma-se aqui o conceito de AVA, que é visto como um espaço de interação, colaboração/cooperação em que a construção do conhecimento é um processo que, apesar de radicalmente individual, é realizado coletivamente. Por isso é um ambiente em que a livre circulação da informação, a hipermídia e a hipertextualidade promovidas pelas tecnologias disponíveis no ambiente o torna um espaço propício para o desenvolvimento da inteligência coletiva. (BEHAR, 2009, p. 174).
\end{abstract}

A autora enfatiza a contemporaneidade como um tempo de múltiplas interações fora e dentro do AVA, que transforma as relações entre pessoas. No ambiente de ensino, em especial o AVA, essas relações se interpenetram e produzem a construção do conhecimento coletivo proporcionado pela interação entre indivíduos viabilizada pela interatividade homem x computador / tablet / smartphone etc.

Dada à complexidade do contexto atual, propõem-se uma análise das teorias da aprendizagem de base Behaviorista, de Pavlov e Skinner; teorias de transição, de Tolman e a Teoria da Gestalt; e as teorias Cognitivas de Piaget e Vygotsky. Tal embasamento teórico tem como objetivo dar sustentação, mesmo que sucinta, para a compreensão do processo de formação do conhecimento, que posteriormente o Design Instrucional - DI - ou seja, o elaborador do AVA e o tutor poderão optar por uma (ou mais) delas para fundamentar seu trabalho.

Outra importante análise é a da Teoria das Inteligências Múltiplas de Howard Gardner, a qual apresenta um estudo sobre os diferentes tipos de inteligências desenvolvidas em maior ou menor intensidade pelo sujeito cognoscente. Gardner 
apresenta: "Numa visão tradicional, a inteligência é definida operacionalmente como a capacidade de responder a itens em testes de inteligência”. (GARDNER, 1993, p. 20). Porém em suas pesquisas defende: "Inteligência implica na capacidade de resolver problemas ou elaborar produtos que são importantes num determinado ambiente ou comunidade cultural". (GARDNER, 1993, p. 21). Portanto, tal estudo possibilita o conhecimento de que existem indivíduos com maiores inclinações que outros para determinados fins. Essa afirmação se torna importante na medida em que o tutor necessita analisar o público alvo e suas expectativas em relação ao AVA, a fim de evitar frustrações e evasões ao longo do curso.

Já, Vasco Pedro Moretto apresenta um estudo sobre os cinco recursos que devem ser mobilizados para o desenvolvimento de competências para resolver situações complexas, o que se torna um aspecto fundamental na educação atual. Tais recursos conteúdos conceituais, desenvolvimento de habilidades, linguagens, valores culturais e administração do emocional - devem ser observados pelo tutor, como um norteador para condução de um ensino para o desenvolvimento de competências, todavia se mantendo próximo ao educando, envolvendo também, interação e aprendizado. (MORETTO, 2014, p. 78).

Patricia Alejandra Behar, desenvolveu um vasto estudo sobre modelos pedagógicos em $\mathrm{EaD}$, que devem servir como referência para todo DI que pretende construir um AVA e para o tutor inserido nesse contexto, como um conhecimento transversal ao seu trabalho docente. Em especial, como está diretamente ligado ao embasamento para a construção de um AVA, torna-se fundamental que o DI seja um profissional de formação multidisciplinar capaz de orientar o seu trabalho de acordo com os princípios - ontológicos, epistemológicos e metodológicos - propostos pela autora. (BEHAR, 2009, p. 149).

Ressalta-se, que outros autores, assim como a Lei de Diretrizes e Bases da Educação Nacional - LDB 9.394/96 - e o Decreto 9.057/17 - que regulamenta o art. 80 da LDB e dispõe sobre Educação a Distância - também foram utilizados no decorrer da pesquisa. Embora se trate de um tema amplo, entende-se que tais abordagens são suficientes para o que se propõe. 
Haja vista a ampliação dos cursos de EaD e seu alto índice de evasão, esse artigo tem como intenção trazer um estudo introdutório sobre do tema: construção de um AVA utilizando-se da interação e do diálogo como forma de aproximar tutor e educando. Todavia, limita-se a trazer tais conhecimentos e não propõe nenhum modelo de AVA, apenas oferece subsídios para que sejam desenvolvidos novos AVA's que priorizem além do desenvolvimento cognitivo, as relações interpessoais, como meio favorável para uma aprendizagem de qualidade.

Portanto, o artigo proposto utiliza somente instrumentos bibliográficos de fontes diversas, seja teórica, legal ou documental; fundamentando seus pressupostos em variados autores que realizaram importantes pesquisas em diferentes campos do conhecimento, como a psicologia, a história da aprendizagem, a educação à distância; assim como o embasamento legal vigente. Logo, constitui-se de uma fonte segura para ser utilizada na construção de AVA's que desejam levar em consideração a interação como um fator importante para o desenvolvimento cognitivo.

\section{ANÁLISE DAS TEORIAS DA APRENDIZAGEM}

Inicialmente, faz-se necessário uma breve análise sobre o desenvolvimento das teorias da aprendizagem, para então compreender a evolução desse processo; de modo que o Designer Instrucional - DI - e o tutor on-line tenham embasamento teórico para desenvolver um AVA e uma aprendizagem de qualidade.

Parte-se do pressuposto que, Teoria é um conjunto de afirmações relacionadas, cuja principal função é resumir e explicar as observações feitas.

Ao longo da história do desenvolvimento humano os pesquisadores foram se aprofundando no estudo do processo de aprendizagem e basicamente sintetizaram suas pesquisas na existência de dois tipos de processos que ocorrem com a finalidade de promover a aprendizagem: Behaviorismo e Cognitivismo.

As teorias Behavioristas baseiam-se em eventos objetivos e observáveis, como estímulos, respostas e recompensas. Os estímulos levam ao comportamento, as respostas são os comportamentos correntes e as recompensas (ou punições) são 
reforçadores ou inibidores para que o comportamento continue ou cesse. Os teóricos behavioristas acreditam que esses são os únicos aspectos do comportamento que podem ser observados, podendo ser usados para desenvolver uma ciência do comportamento humano.

Entre as teorias Behavioritas as mais populares são as desenvolvidas por Pavlov - Condicionamento Clássico - e a de Skinner - Condicionamento Operante. Pavlov após vários experimentos científicos com cães observou que o cão ao ver o alimento (estímulo incondicionado) começa a salivar (resposta incondicionada), se tocada uma campainha (estímulo condicionado) antes de apresentar o alimento nada acontece; porém realizado o toque da campainha repetidas vezes e depois apresentado o alimento, o cão passa a salivar somente ao ouvir a campainha. Concluiu então, que seria possível, através de estímulos, controlar o comportamento humano e assim condicionar o homem a qualquer tipo de aprendizagem. Já Skinner, com seu Condicionamento Clássico, aprofundou os estudos de Pavlov e concluiu que além dos estímulos e respostas existem também variáveis que influenciam no comportamento, como o uso de recompensas (aumentam as chances de o comportamento permanecer) e punições (reduzem as possibilidades de repetição do comportamento).

Em seguida, surgiram às teorias de transição entre Behaviorismo e Cognitivismo, podem-se citar o teórico Tolman e a Teoria da Gestalt. Tolman - e sua Teoria do Behaviorismo Intencional - acreditava que todo comportamento tem uma intenção e é direcionado para um objetivo pela cognição. $\mathrm{O}$ comportamento nunca seria apenas o resultado de estímulos e respostas sem pensamento. Já a Teoria da Gestalt afirmava que o todo é maior do que a soma das partes, com isso pretendia dizer que as soluções só são encontradas através da soma de um conjunto de fatores, que juntos conduzem ao insight, ou seja, a ideia para a solução de uma determinada situação.

Em relação ao Cognitivismo, Guy R. Lefrançois afirma: "é uma abordagem psicológica que se preocupa mais com a tomada de decisões, pensamento, solução de problemas, imaginação e tópicos relacionados do que única, ou primariamente, com o comportamento observável” (LEFRANÇOIS, 2015, p. 197). Citam-se os teóricos Piaget e sua Epistemologia Genética e Vygotsky com sua Teoria Cultural/Cognitiva. Piaget acredita que o desenvolvimento humano é um processo de adaptação e a mais alta forma 
de adaptação é a cognição. Dentre suas contribuições para a educação estão: o processo de adaptação (assimilação e acomodação), quando o sujeito primeiro assimila o novo e depois o acomoda produzindo mudança em seu comportamento; e os estágios cognitivos, classificando em cada faixa etária os processos cognitivos que envolvem o indivíduo. Já Vygotsky apresentou o conceito de Zona de Desenvolvimento Proximal ZDP: quando o ser humano é capaz de realizar atividades sozinho está em seu Desenvolvimento Real; quando conta com o auxílio de outro indivíduo pode ampliar suas habilidades e produzir novo conhecimento, está na ZDP; objetivando chegar ao Desenvolvimento Potencial. Sua outra contribuição importante foi o estudo sobre a linguagem e a cultura que têm influência direta no desenvolvimento cognitivo, social e afetivo; sendo o conhecimento considerado uma construção de fora para dentro do sujeito cognoscente.

Após essa breve análise o DI e o tutor podem tirar suas conclusões sobre o processo de desenvolvimento da aprendizagem de modo a utilizar recursos instrucionais adequados para o fim a que se destinam, optando pela teoria que mais se afina com os objetivos do curso, o tipo de conhecimento que pretendem produzir e o público que querem alcançar. Logo, é fundamental que tenham um embasamento teórico para definir seus pressupostos filosóficos a fim de dar direcionamento a sua ação.

Outro estudo de relevância singular para o desenvolvimento da aprendizagem foi o realizado por Howard Gardner, denominado Teoria das Inteligências Múltiplas. Implicado pelas testagens formais de conhecimento (o mais utilizado e famoso é o teste do Coeficiente de Inteligência - QI - desenvolvido por Binet e Simon e altamente considerado até os dias atuais); Gardner propõe que seja considerada a diversidade de inteligências que o ser humano possui em maior ou menor grau. O cientista mapeou sete tipos de inteligência - linguística, lógico-matemática, espacial, musical, corporalcenestésica, interpessoal e intrapessoal - e propôs que desde a infância os sujeitos pudessem ser estimulados na inteligência que mais se sobrepõe a ele, assim cada indivíduo poderia se especializar em uma área e desenvolver domínios de conhecimento que permitiriam grandes contribuições para a sociedade.

Esse esclarecimento proporciona ao tutor desenvolver um processo de ensinoaprendizagem considerando a diversidade de inteligências de modo a direcionar os 
materiais educacionais para potencializar determinado domínio, promovendo uma educação e um processo de avaliação justo para com a inteligência do educando.

O mestre em Didática, Vasco Pedro Moretto, desenvolveu cinco recursos que devem ser considerados para o desenvolvimento de competências e habilidades, que são: conteúdos conceituais, desenvolvimento de habilidades, linguagens, valores culturais e administração do emocional. A sua proposta é que esses recursos sejam utilizados como um norteador para o desenvolvimento da aprendizagem, pois abarcam o indivíduo por completo, em seus aspectos cognitivos, sociais, afetivos e emocionais. Logo, se torna uma excelente proposta para que o tutor se oriente de modo a considerar as especificidades do sujeito cognoscente que estão diretamente relacionadas com o processo de ensino aprendizagem.

Em relação específica a Educação a Distância - EaD, cita-se a Doutora e Mestre em Ciência da Computação, Patricia Alejandra Behar, que dentre suas muitas contribuições para a $\mathrm{EaD}$, apresenta os princípios - ontológicos, epistemológicos e metodológicos - para a formação de modelos pedagógicos para a construção do AVA. Para o que propõe o presente artigo, são mencionados apenas os princípios ontológicos, com suas dimensões e descritores da cibercultura.

Acrescenta-se, ainda, a significativa contribuição do pedagogo contemporâneo da complexidade Edgar Morin, que enfatiza a importância de pesquisas no ramo da EaD com o intuito de criar novas alternativas pedagógicas para a educação. Cita-se:

A scienza nuova não destrói as alternativas clássicas, e não traz uma solução monista que seria como a essência da verdade. Mas os termos alternativos tornam-se antagônicos, contraditórios e complementares ao mesmo tempo no seio de uma visão mais ampla, que vai ter de enfrentar e encontrar novas alternativa. (MORIN, 1990, p. 79).

Embasado por referenciais teóricos da aprendizagem e movida por essas discussões acerca da $\mathrm{EaD}$ e da sua complexidade, criou-se um quadro referencial para os princípios ontológicos que devem ser analisados a fim de construir um AVA e manter a constante interação entre tutor e educando. Deve-se, no entanto, destacar que a nomenclatura dos descritores ontológicos foi realizada por BEHAR (BEHAR, 2009, 
p.171), contudo, a definição dos mesmos, é fruto de pesquisa em diferentes bibliografias (vide referências bibliográficas).

Quadro 1 - Quadro referencial dos princípios ontológicos

\begin{tabular}{|c|c|c|c|}
\hline $\begin{array}{c}\text { Dimensão } \\
\text { Temporal/Espaci } \\
\text { al }\end{array}$ & Dimensão Tecnológica & Dimensão do Sujeito & $\begin{array}{c}\text { Dimensão } \\
\text { Educacional }\end{array}$ \\
\hline $\begin{array}{l}\text { Mobilidade: } \\
\text { referente aos } \\
\text { sujeitos e as } \\
\text { funcionalidades } \\
\text { do AVA. }\end{array}$ & $\begin{array}{lr}\text { Colaboração/Cooperaçã } \\
\text { o: trabalho realizado } \\
\text { pela } \\
\text { multidisciplinar } \\
\text { construção na } \\
\text { hipertextualidade } \\
\text { AVA. }\end{array}$ & $\begin{array}{l}\text { Autonomia/Dependênci } \\
\text { a: o sujeito na relação } \\
\text { com o AVA constrói e } \\
\text { reconstrói sua } \\
\text { autonomia } \\
\text { dependência. }\end{array}$ & $\begin{array}{l}\text { Protagonismo: } \\
\text { a } \\
\text { possibilidade } \\
\text { dos sujeitos se } \\
\text { tornarem } \\
\text { protagonistas, } \\
\text { com postura } \\
\text { ativa. }\end{array}$ \\
\hline $\begin{array}{l}\text { Flexibilidade: em } \\
\text { relação ao horário } \\
\text { para acesso. }\end{array}$ & $\begin{array}{l}\text { Inteligência coletiva: } \\
\text { construída por meio das } \\
\text { trocas de mensagens. }\end{array}$ & $\begin{array}{l}\text { Autoria: o sujeito } \\
\text { contribui para a } \\
\text { construção coletiva do } \\
\text { conhecimento, é autor. }\end{array}$ & $\begin{array}{l}\text { Polifonia: o } \\
\text { sujeito } \\
\text { contribui com } \\
\text { diversos } \\
\text { materiais } \\
\text { produzidos no } \\
\text { AVA. Todos } \\
\text { tem voz e vez. }\end{array}$ \\
\hline $\begin{array}{l}\text { Alinearidade: } \\
\text { acesso ao AVA } \\
\text { em qualquer } \\
\text { tempo, lugar e } \\
\text { horário. }\end{array}$ & $\begin{array}{l}\text { Hipermídia: diferentes } \\
\text { meios de disponibilizar } \\
\text { a informação (textos, } \\
\text { imagens, sons). }\end{array}$ & $\begin{array}{l}\text { Auto-organização: o } \\
\text { sujeito necessita da } \\
\text { relação com o outro } \\
\text { para se conhecer e se } \\
\text { transformar. }\end{array}$ & $\begin{array}{l}\text { Exterioridade: } \\
\text { conexão que o } \\
\text { sujeito faz } \\
\text { com o que é } \\
\text { tratado no }\end{array}$ \\
\hline
\end{tabular}




\begin{tabular}{|c|c|c|c|}
\hline & & & $\begin{array}{l}\text { AVA e fora } \\
\text { dele. }\end{array}$ \\
\hline $\begin{array}{l}\text { Presenteísmo: } \\
\text { tempos é sempre o } \\
\text { presente, } \\
\text { momento } \quad \text { da } \\
\text { conexão. }\end{array}$ & $\begin{array}{l}\text { Livre circulação da } \\
\text { informação: } \\
\text { informação é difundida } \\
\text { de forma transversal, } \\
\text { aleatória e associativa. }\end{array}$ & $\begin{array}{l}\text { Descentração: o sujeito } \\
\text { se entende como centro } \\
\text { de referência e toma } \\
\text { distância para ver como } \\
\text { o outro o vê. }\end{array}$ & $\begin{array}{l}\text { Interconexão: } \\
\text { entre os } \\
\text { caminhos que } \\
\text { o sujeito } \\
\text { percorreu } \\
\text { dentro e fora } \\
\text { do AVA para } \\
\text { a construção } \\
\text { do seu } \\
\text { conhecimento. }\end{array}$ \\
\hline $\begin{array}{l}\text { Velocidade: no } \\
\text { acesso, no } \\
\text { processamento } \mathrm{e} \\
\text { na produção dos } \\
\text { dados. }\end{array}$ & $\begin{array}{l}\text { Hipertextualidade: } \\
\text { usuário pode escolher o } \\
\text { caminho que percorre e } \\
\text { construir novos. }\end{array}$ & $\begin{array}{l}\text { Conexão: apesar da sua } \\
\text { individualidade, } \\
\text { sujeito necessita estar } \\
\text { conectado com o } \\
\text { mundo e com o outro. }\end{array}$ & $\begin{array}{l}\text { Mobilidade } \\
\text { dos centros: o } \\
\text { professor não } \\
\text { é mais o } \\
\text { centro do } \\
\text { processo. }\end{array}$ \\
\hline $\begin{array}{l}\text { Eficiência: AVA } \\
\text { eficaz dentro de } \\
\text { sua proposta de } \\
\text { uso. }\end{array}$ & $\begin{array}{l}\text { Interação: desenvolver } \\
\text { a interação entre } \\
\text { usuários. }\end{array}$ & & $\begin{array}{l}\text { Metamorfose: } \\
\text { as } \\
\text { funcionalidad } \\
\text { es do AVA } \\
\text { são } \\
\text { ressignificada } \\
\text { s conforme o } \\
\text { interesse e } \\
\text { necessidade } \\
\text { dos sujeitos. }\end{array}$ \\
\hline Pertinência: AVA & & & \\
\hline
\end{tabular}


útil em relação aos objetivos

propostos.

Fonte: Elaboração da autora, 2018.

Nesse contexto, o DI - juntamente com o tutor e demais membros da equipe multidisciplinar - tomam conhecimento dos princípios norteadores para $\mathrm{o}$ desenvolvimento do AVA. O que gera a responsabilidade de avaliar constantemente se a proposta de ensino está adequada ao objetivo do AVA, realizando o feedback contínuo para a melhoria do ambiente. Logo, a participação do tutor é fundamental nesse momento, pois que por possuir contato direto, pode analisar se o educando está encontrando dificuldades ou se está adaptado ao ambiente.

\section{ANÁLISE DA LEGISLAÇÃO VIGENTE}

Em relação à legislação, no ano de 2017 o Decreto 5.622/05 - que regulamentava o art. 80 da Lei no 9.394, de 20 de dezembro de 1996, que estabelece as diretrizes e bases da educação nacional - foi revogado pelo Decreto 9.057/17; que trouxe algumas inovações e flexibilizou o uso da modalidade EaD na educação formal. Citam-se os artigos:

Art. 2o A educação básica e a educação superior poderão ser ofertadas na modalidade a distância nos termos deste Decreto, observadas as condições de acessibilidade que devem ser asseguradas nos espaços e meios utilizados.

Art. 4 As atividades presenciais, como tutorias, avaliações, estágios, práticas profissionais e de laboratório e defesa de trabalhos, previstas nos projetos pedagógicos ou de desenvolvimento da instituição de ensino e do curso, serão realizadas na sede da instituição de ensino, nos polos de educação a distância ou em ambiente profissional, conforme as Diretrizes Curriculares Nacionais.

Art. 11. As instituições de ensino superior privadas deverão solicitar credenciamento para a oferta de cursos superiores na modalidade a distância ao Ministério da Educação.

$\S 2$ o É permitido o credenciamento de instituição de ensino superior exclusivamente para oferta de cursos de graduação e de pós-graduação lato sensu na modalidade a distância. 
Art. 15. Os cursos de pós graduação lato sensu na modalidade a distância poderão ter as atividades presenciais realizadas em locais distintos da sede ou dos polos de educação a distância.

Acrescenta-se que, a Lei de Diretrizes e Bases da Educação Nacional - LDB 9.394/96 - também passou por uma reformulação recente, a qual deu maior ênfase a modalidade de ensino EaD, especialmente no Ensino Médio. Ressalta-se o artigo:

Art. 36. O currículo do ensino médio será composto pela Base Nacional Comum Curricular e por itinerários formativos, que deverão ser organizados por meio da oferta de diferentes arranjos curriculares, conforme a relevância para o contexto local e a possibilidade dos sistemas de ensino, a saber:

I - linguagens e suas tecnologias;

II - matemática e suas tecnologias;

III - ciências da natureza e suas tecnologias;

IV - ciências humanas e sociais aplicadas;

$\mathrm{V}$ - formação técnica e profissional.

$\S$ 11. Para efeito de cumprimento das exigências curriculares do ensino médio, os sistemas de ensino poderão reconhecer competências e firmar convênios com instituições de educação a distância com notório reconhecimento, mediante as seguintes formas de comprovação:

I - demonstração prática;

II - experiência de trabalho supervisionado ou outra experiência adquirida fora do ambiente escolar;

III - atividades de educação técnica oferecidas em outras instituições de ensino credenciadas;

IV - cursos oferecidos por centros ou programas ocupacionais;

$\mathrm{V}$ - estudos realizados em instituições de ensino nacionais ou estrangeiras;

VI - cursos realizados por meio de educação a distância ou educação presencial mediada por tecnologias.

Percebe-se que o governo brasileiro tem realizado esforços no sentido de popularizar a modalidade de ensino em $\mathrm{EaD}$, dando maior flexibilidade e desburocratizando as instituições de ensino para que haja maior celeridade e adequação ao contexto social no qual a sociedade está inserida.

No que compete ao tutor, é necessário estar atento a essas modificações legais para que haja adequação às propostas governamentais, não somente no sentido da 
regulamentação, mas efetivamente para proceder de acordo com a nova filosofia do governo de expandir a educação em todos os níveis para toda a população.

\title{
5. FUNÇÕES DO TUTOR ON-LINE NO AVA
}

Em um mundo que muda rapidamente, professores procuram auxiliar seus alunos a analisar situações complexas e inesperadas: a desenvolver a criatividade; a utilizar outros tipos de "racionalidade"; a imaginação criadora; a sensibilidade tátil, visual e auditiva; entre outras. $\mathrm{O}$ respeito as diferenças e o sentido de responsabilidade são outros aspectos que os professores procuram trabalhar com seus alunos. Aprender a ser - professores e alunos cidadãos do país e do mundo é uma necessidade advinda com as parcerias e projetos educacionais em rede. (KENSKI, 2015, p. 93)

É possível notar que as relações ensino-aprendizagem sofreram profundas mudanças nos últimos anos, agregando ao educador uma série de novas atribuições. Também mudaram-se os meios pelos quais se faz o aprender e logo essas tantas atribuições também se estenderam a essas outros modelos de "salas de aula". Desse modo, é importante que o tutor on-line esteja atento a essas novas atribuições e pratique uma formação continuada a fim de atender a essas novas demandas da sociedade.

\begin{abstract}
A relação professor-aluno pode ser profundamente alterada pelo uso das TICs, em especial se estas forem utilizadas intensamente. Na resolução de um problema, na realização de um projeto, na coleta e na análise de dados sobre um determinado assunto, o professor realiza um mergulho junto com os alunos, para poder responder as suas dúvidas e questões. A proximidade com os alunos ajuda-o a compreender suas ideias, olhar o conhecimento de novas perspectivas e a aprender também. As TICs proporcionam um novo tipo de interação do professor com os alunos. (KENSKI, 2015, p. 103)
\end{abstract}

O tutor é o elo entre o AVA e o educando, é um educador que está à disposição do educando para que haja uma interatividade produtiva entre ele e o Material Educacional Digital - MED. É o animador, o motivador, é quem acompanha o desenvolvimento da aprendizagem e produz uma interação amigável, de modo que o educando se familiarize com o AVA e se sinta assistido. O tutor tem, também, a tarefa de mediar interações entre educandos, acompanhar a assiduidade, o acesso às aulas, 
corrigir tarefas e atribuir notas etc. É o educador da sala de aula convencional, com a tarefa primordial de (na distância) estabelecer-se presente na vida do educando, motivando-o e conduzindo-o rumo à aprendizagem de qualidade em AVA.

Com tantas atribuições, o tutor deve, ainda, ser um exímio estudante e pesquisador, tendo em vista que além das competências como docente - já que muitas vezes, produz o conteúdo pedagógico que será convertido em MED - também deve atualizar-se quanto as Tecnologias da Informação e Comunicação - TIC's - e quanto as principais tendências da educação on-line, de modo que traga novas possibilidades para o curso e mantenha um diálogo atualizado com os educandos.

É importante ressaltar que o tutor deve ter uma postura ética e encorajadora, no sentido de não fazer distinção entre os educandos e ter a competência para respeitar os conhecimentos prévios dos mesmos, considerando o currículo oculto que se faz presente em todo processo de ensino. Dessa forma, não menosprezar educandos por um modo simples de escrever, ou até por vezes errado; mas de modo sutil, encorajá-lo a estudar a norma culta, a se adequar ao ambiente acadêmico de modo que ele compreenda que seus conhecimentos sociais de vida prática tem seu valor, mas que no mundo acadêmico deve-se seguir um padrão de linguagem. Essa e muitas outras orientações podem e devem ser dadas pelo tutor, assim o educando desenvolve outras competências além da que se destina o curso e certamente será encorajado a iniciar outros curso em EaD.

Outra função muito importante do tutor é seu posicionamento em relação à avaliação.

Sendo assim, a avaliação em AVAs pode ser entendida a partir de três perspectivas:

a) Avaliação por meio de testes on-line;

b) Avaliação da produção individual dos estudantes;

c) análise das interações entre alunos, a partir de mensagens postadas/ trocadas por meio das diversas ferramentas de comunicação. (BEHAR, 2009, p. 100)

O tutor deve averiguar quando há dúvidas e orientar o educando que refaça seu trabalho, não por vaidade docente, mas deixando-o consciente de que ao dissertar um texto ele desenvolve habilidades cognitivas muito importantes para sua própria 
aprendizagem. Assim, cria-se um vínculo de respeito entre o trabalho de ambos e aumenta a autoconfiança do educando, que se sentirá assistido e capaz de produzir.

Ainda sobre a avaliação, entende-se que:

\begin{abstract}
A avaliação é um processo de múltiplas facetas, incluindo os aspectos afetivos e sociais envolvidos na aprendizagem. Logo, acreditamos que a avaliação não pode ser conduzida somente de forma eletrônica, independentemente do ambiente de aprendizagem adotado, ou seja, sala de aula ou ambiente computacional, a avaliação do estudante é uma tarefa do professor. (CAMPOS, 2003, p. 124)
\end{abstract}

Novamente, torna-se evidente a necessidade do tutor on-line estar atento nesse importante processo de interação entre ele e seu educando. Pois a avaliação não é somente uma demonstração do que foi aprendido, mas principalmente do que não produziu conhecimento. É nesse momento que a intervenção deve ser efetiva a fim de sanar deficiências e não simplesmente para atribuição de notas.

Portanto, o tutor em EaD é o educador, o elo para que a interatividade ocorra com eficácia, o amigo, o conselheiro, o animador, o motivador, o incentivador, o facilitador etc; ou seja, é o profissional responsável por fazer com que o educando continue o curso e se sinta feliz ao estudar. Suas atribuições são inúmeras, tendo em vista que conquistar um educando quando não se está presente é uma tarefa árdua que requer desse profissional conhecimentos: acadêmicos, didáticos, pedagógicos, sociais, afetivos e psicológicos. Desse modo, sua formação e sua prática devem ser múltiplas e fundamentalmente éticas.

\title{
6. CONSIDERAÇÕES FINAIS
}

Diante do exposto, evoca-se que o artigo proposto surgiu da inquietação sobre as múltiplas interações que ocorrem no mundo contemporâneo fora do AVA e que se interpenetram nesse ambiente de ensino, produzindo a construção do conhecimento coletivo, proporcionado pela interação entre indivíduos viabilizada pela interatividade homem x computador / tablet / smartphone etc. Essa rede de relações presente no ciberespaço invade o AVA, de modo que hoje, no processo de ensino-aprendizagem 
virtual é imprescindível que o tutor estabeleça laços de interação com o educando para produção do conhecimento. Dessa forma, desperta-se para a necessidade de desenvolver AVA's e a interação tutor $\mathrm{x}$ educando com esse olhar afetivo que considere a individualidade deste.

Para tanto, faz-se necessário um estudo sobre as teorias de aprendizagem de modo a subsidiar a construção de AVA's e a dar suporte ao tutor sobre o processo da cognição. Após a análise, o DI e o tutor podem tirar suas conclusões sobre o processo de desenvolvimento da aprendizagem de modo a utilizar recursos instrucionais adequados para o fim a que se destinam, optando pela teoria que mais se afina com os objetivos do curso, o tipo de conhecimento que pretendem produzir e o público que querem alcançar. Logo, é fundamental que tenham embasamento teórico para definir seus pressupostos filosóficos, a fim de dar direcionamento as suas ações.

Realizou-se, também, uma análise sucinta sobre as recentes modificações na legislação em relação à modalidade de ensino em $\mathrm{EaD}$, demonstrando a preocupação do governo em adequar a educação brasileira ao contexto social mundial, que exige um ensino mais dinâmico, interativo e de maior expansão. Desse modo, é importante que o tutor on-line se mantenha atualizado com a lei e atento aos pressupostos filosóficos que a nação está professando, rumo ao desenvolvimento do país.

Em seguida parte-se para a análise das funções do tutor no AVA e a construção desse ambiente considerando o aspecto da interação. O tutor é o elo entre o AVA e o educando, é um professor que está à disposição do educando para que haja uma interatividade produtiva entre aluno e o MED. É o animador, o motivador, é quem acompanha o desenvolvimento da aprendizagem do aluno e produz uma interação amigável, de modo que o educando se familiarize com o AVA e se sinta assistido. O tutor tem, também, a tarefa de mediar interações entre alunos, acompanhar a assiduidade, o acesso às aulas, corrigir tarefas e atribuir notas etc. É o educador da sala de aula convencional, com a tarefa primordial de (na distância) tornar-se presente na vida do aluno, motivando-o e conduzindo-o rumo à aprendizagem relevante no AVA.

Portanto, conclui-se que o presente artigo é uma excelente proposta para que o DI, o tutor e os demais membros da equipe multidisciplinar tomem conhecimento dos 
princípios norteadores para o desenvolvimento do AVA. O que gera a responsabilidade de avaliar constantemente se a proposta de ensino está adequada ao que o AVA propõe, realizando o feedback contínuo para a melhoria do ambiente. E em especial em relação ao tutor, o artigo torna-se uma boa opção para que se oriente de modo a considerar as especificidades cognitivas e afetivas do sujeito cognoscente, que estão diretamente relacionadas com a eficácia do processo ensino e aprendizagem.

\section{REFERÊNCIAS}

BEHAR, Patrícia Alejandra (orgs.). Modelos pedagógicos em educação a distância. Porto Alegre: Artmed, 2009.

BRASIL. Presidência da República. Decreto $n^{\circ}$ 9.057, de 25 de maio de 2017. Regulamenta o art. 80 da Lei $\mathrm{n}^{\circ}$ 9.394, de 20 de dezembro de 1996, que estabelece as Diretrizes e Bases da Educação Nacional. Brasília: Presidência da República, 2017. Disponível em: <http://www.planalto.gov.br/ccivil_03/_ato20152018/2017/decreto/D9057.htm>. Acesso em: 19 dez.2018.

Presidência da República. Lei n ${ }^{\circ}$ 9.394, de 20 de dezembro de 1996. Estabelece as Diretrizes e Bases da Educação Nacional. Brasília: Presidência da República, 1996. Disponível em: <http://www.planalto.gov.br/Ccivil_03/leis/L9394.htm>. Acesso em: 19 dez.2018.

CAMPOS, Fernanda C. A. et al. Cooperação e aprendizagem on-line. Rio de Janeiro: DP\&A, 2003.

FARIA, Adriano Antônio. O QUE E O QUEM DA EAD: história e fundamentos. Ed. Intersaberes.2013. 
GUAREZI, Rita de Cássia Menegaz. Educação a Distância sem Segredos, Ed. Intersaberes. 2012.

KENSKI, Vani Moreira. Educação e Tecnologias: o Novo Ritmo da Informação. 8.ed. Campinas, SP: Papirus, 2012.

Tecnologias e Tempo Docente, Ed. Papirus. 2013.

LIBÂNEO, Jose Carlos. Didática. 2.ed. São Paulo: Cortez, 2013.

MAIA, Carmen. ABC da EAD, Ed. Pearson Prentice Hall, São Paulo. 2007.

MOORE, Michael G.; KEARSLEY, Greg. Educação a Distância: uma visão integrada. São Paulo: Thonson Learnig, 2007.

MOREIRA, Antonio Flavio; TADEU, Tomaz (orgs). Currículo, cultura e sociedade. 12.ed. Sao Paulo: Cortez, 2011.

MORETTO, Vasco Pedro. Planejamento - Planejando a Educação para o Desenvolvimento de Competências. 9.ed. Petrópolis: Vozes, 2013.

MORIN, Edgar. Introdução ao pensamento complexo. Lisboa: Instituto Piaget, 1990.

SEVERINO, Antonio Joaquim. Metodologia do Trabalho Científico. 23.ed. rev. e atual. Sao Paulo: Cortez, 2007.

SILVA, Andreza Regina Lopes da; ESPANHOL, Fernando José. Design Instrucional: a construção do conhecimento na EaD. SP: Paco, 2014. 


\section{Priscila da Silva Rodrigues Machado}

Pós-graduada em Educação a Distância e Tutoria em Educação a Distância pela Faculdade Internacional Signorelli.

Artigo recebido em 20/12/2018

Aceito para publicação em 29/07/2019

Para citar este trabalho:

MACHADO, Priscila da Silva Rodrigues. APRENDIZAGEM EM EDUCAÇÃO A DISTÂNCIA - EAD: O DESAFIO DA FORMAÇÃO DE TUTORES ON-LINE, COM ÊNFASE NO RELACIONAMENTO INTERPESSOAL EM AMBIENTES VIRTUAIS DE APRENDIZAGEM - AVA. Revista Paidéi@. Unimes Virtual. Volume 11 - Número 20 -JULHO-2019. Disponível em:

http://periodicos.unimesvirtual.com.br/index.php/paideia/index 